\title{
Blokezko kopolimero eta nanopartikula magnetikoetan oinarritutako nanokonposatu film meheak: nanopartikulen dispertsioaren eragina
}

\author{
(Block copolymer and magnetic nanoparticle based thin \\ film nanocomposites: effect of nanoparticle dispersion)
}

Irati Barandiaran, Galder Kortaberria

\begin{abstract}
«Materialak + Teknologia» Taldea, Ingeniaritza Kimiko eta Ingurugiro Ingeniaritza Saila, Euskal Herriko Unibertsitatea UPV/EHU, Gipuzkoako Ingeniaritza Eskola, Europa Plaza 1, 20018 Donostia
\end{abstract}

irati.barandiaran@ehu.eus / galder.cortaberria@ehu.eus

DOI: $10.1387 /$ ekaia.17883

Jasoa: 2017-05-25

Onartua: 2017-07-10

Laburpena: Nanokonposatu organiko/inorganikoak gizartean sortzen ari diren behar berriei erantzuteko hautagai egokiak dira, izan nanoelektronikan, fotonikan, energiapilaketan, katalisian, estalduretan, etab. Horien artean blokezko kopolimero eta nanopartikula magnetikoetan oinarritutako nanokonposatuak dauzkagu, zeintzuek aplikazio horietarako propietate interesgarriak dituzten. Lan honetan blokezko kopolimero eta nanopartikula magnetikoz osatutako nanokonposatu film meheak aztertu dira, nanopartikulen dispertsiorako teknika desberdinak landuz eta horiek blokezko kopolimeroen nanoegituraketan duten eragina aztertuz, baita nanokonposatuei transferitutako propietate magnetikoak ere.

Hitz gakoak: blokezko kopolimero, nanopartikula magnetiko, nanokonposatu film mehe, nanopartikulen dispertsioa.

\begin{abstract}
Organic/inorganic nanocomposites are adequate candidates to respond to the new needs of the society regarding to nanoelectronics, photonics, energy-storing, catalysis, coatings and others. Among those new materials nanocomposites based on block copolymer and magnetic nanoparticles present interesting properties for mentioned applications. In this work nanocomposites based on block copolymers and magnetic nanoparticles have been analyzed, studying new methods to disperse nanoparticles and the effect of those nanoparticles in the nanostructure of the block copolymers.
\end{abstract}


In addition, the transfer of the magnetic properties of nanoparticles to the nanocomposites has also been studied.

Keywords: block copolymer, magnetic nanoparticle, thin film nanocomposite, nanoparticle dispersion.

\section{SARRERA}

Material nanokonposatuak material solido multifasikoak dira, zeintzuetan gutxienez faseetako batek dimentsio bat, bi edo hirurak $100 \mathrm{~nm}$ baino gutxiagokoa izan behar duen, edota materiala osatzen duten faseen arteko distantzia errepikakorra eskala nanometrikoan duten egiturak. Material nanokonposatuak hainbat motatakoak izan daitezkeen arren, lan honetan aztertuko direnak matrize polimerikoa duten material nanokonposatu organiko/inorganikoak dira, hain zuzen ere, blokezko kopolimero eta nanopartikula magnetikoetan oinarritutakoak.

Blokezko kopolimeroek nanoegiturak sortzeko duten gaitasuna dela eta, interes handia piztu dute $[1,2]$. Kopolimeroak konposizio kimiko desberdina duten polimero-kate batez baino gehiagoz osatuta dauden makromolekulak dira, kimikoki desberdinak diren polimero-kate horiek elkarren artean lotura kobalentez elkartuta daudelarik. Kopolimeroak sintetizatzerakoan, arkitektura desberdinak osa daitezke kopolimeroa osatzen duten kateak berauen artean elkartzeko moduaren arabera; hala nola, ausazkoak izan daitezke, di edo tribloke motakoak, txertatuak edota izar-forma duten kopolimeroak (1. irudia).

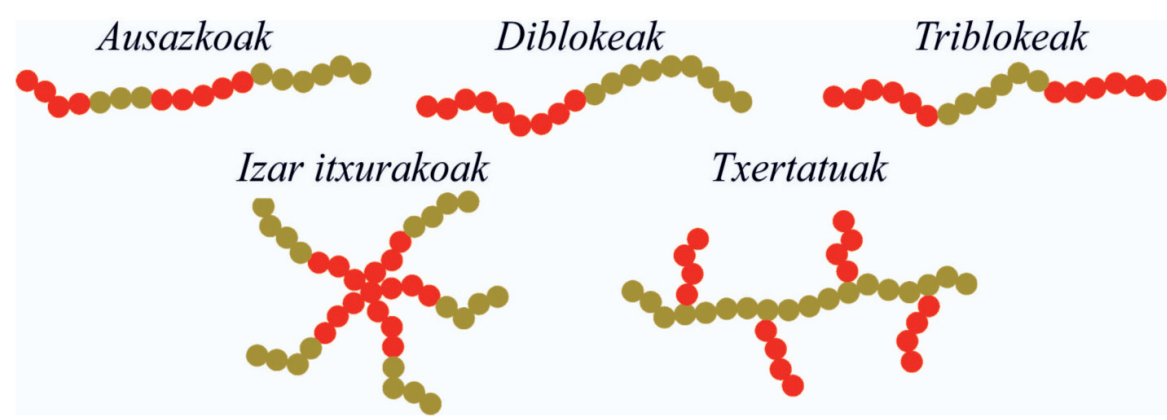

1. irudia. Kopolimeroen arkitektura desberdinak.

Blokezko kopolimeroa osatzen duten polimero-kate desberdinen arteko bateraezintasun termodinamikoak fase-bereizketa eragiten du. Baina blokezko kopolimeroen kasuan, polimero-kate desberdin horiek lotura koba- 
Blokezko kopolimero eta nanopartikula magnetikoetan oinarritutako nanokonposatu film meheak: nanopartikulen dispertsioaren eragina

lentez elkartuta egoteak fase-bereizketa eskala nanometrikoan gauzatzea eragiten du, horrela nanoegiturak sortuz [3]. Blokezko kopolimeroek sortutako nanoegiturak hainbat parametroren araberakoak dira, besteak beste, kopolimeroaren konposizioa $(f)$, blokeen arteko Flory-Huggins interakzioparametroa $(\chi)$ eta kopolimeroaren polimerizazio-gradua $(N)$. Diblokezko kopolimeroekin lortutako morfologia ohikoenak izan masan edo izan film meheetan, 2. irudian ikus daitekeen bezala, esferikoa, zilindrikoa, giroidala eta lamelarra dira [4].

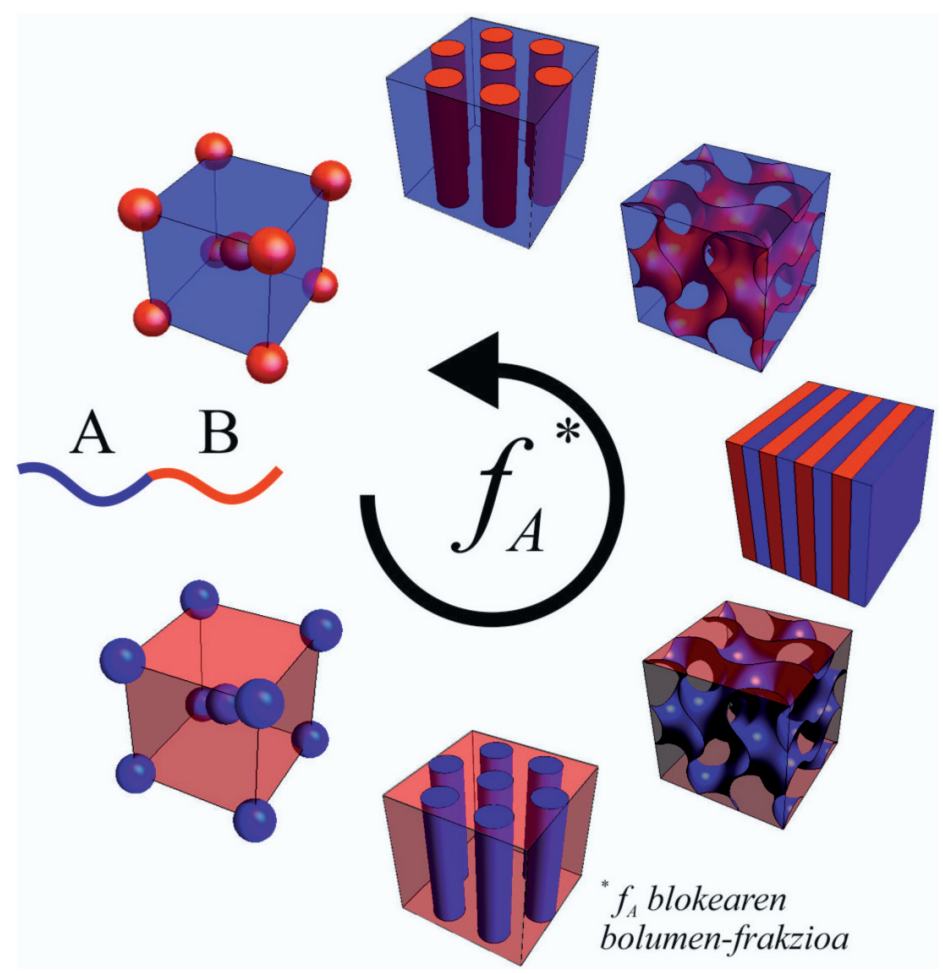

2. irudia. Diblokezko kopolimeroen nanoegiturak segmentu bakoitzeko bolumen-frakzioaren arabera.

Nanoegituratutako blokezko kopolimero horiei nanopartikula inorganikoak gehitzeak materiala propietate berriekin dohaintzen du. Arlo honetan egindako ikerketek erakutsi dute amaierako nanokonposatuaren propietateak erabilitako matrize polimerikoaren, gehitutako nanopartikulen eta horien dispertsioaren araberakoak direla. Gehitutako nanopartikula horiek ugariak izan daitezke, hortaz, baita material berriari eskainitako propietateak ere $\left(\mathrm{CdSe}-\mathrm{a}, \mathrm{TiO}_{2}-\mathrm{a}, \mathrm{PbTe}-\mathrm{a} . ..\right)$ [5-7]. Horien guztien artean, burdin 
oxidozko nanopartikulek interes berezia piztu dute beraien propietate magnetiko eta optikoak direla medio, eta baita bio-bateragarriak eta ez-toxikoak izan daitezkeelako ere [8]. Hori dela eta, lan ugari argitaratu izan dira blokezko kopolimero eta nanopartikula magnetikoetan oinarritutako nanokonposatuen inguruan [9-11].

Nanopartikulekin jarraituz, esan beharra dago dispertsioak garrantzi handia duela nanopartikula inorganikoak dituzten nanokonposatuak prestatzerako orduan; izan ere, nanopartikulek beraien gainazaleko indarrak direla-eta elkartzeko joera dute, nanopartikulez osatutako agregatu handiak sortuz. Hori dela eta, saiakera berezia eskatzen du nanopartikulen dispertsioa aztertzeak eta hobetzeak. Hori gauzatzeko metodo desberdinak egon arren, denek printzipio bera dute oinarrian, nanopartikulen gainazaleko tentsioak aldatu, beraien artean elkartzeko joera ekiditeko eta matrizearekiko duten bateragarritasuna hobetzeko. Hori gauzatzeko metodo desberdinak aztertu izan dira, besteak beste surfaktanteak erabiltzea [9] edota nanopartikulen gainazalera polimero kateak atxikitzea [10]. Ikerketa-lan honetan bigarren metodo hori aztertu da; horretarako, ezagutzen diren hiru metodo desberdinak aztertu direlarik: grafting to, grafting through eta grafting from.

\section{NANOPARTIKULEN ERALDATZEA}

Esan bezala, ikerketa-lan honetan nanopartikulen dispertsioa hobetzeko hainbat polimero-kate atxiki zaizkie $\mathrm{Fe}_{2} \mathrm{O}_{3}$ nanopartikulei metodo desberdinak jarraituz.

Hasteko grafting to metodoa erabiliz, amaieran kloro taldea duen poli(metil metakrilato- $b$ - $\varepsilon$-kaprolaktona) ( $C l$-PMMA- $b$-PCL) blokezko kopolimeroa atxiki zaie nanopartikulei. Teknika hau erabili ahal izateko, beharrezkoa da kate polimerikoak amaieran talde funtzional bat edukitzea, kasu honetan kloroa, nanopartikulen gainazaleko gune erreaktiboekin erreakzionatu eta nanopartikulari atxikitzeko.

Bestetik, grafting through teknika jarraituz poli(metil metakrilato) (PMMA) edo poliestireno (PS) kateak txertatu zaizkie nanopartikulei. Teknika honetan nanopartikulei atxikitzen zaizkien molekulek talde polimerizagarri bat dute, polimeroa horren baitan hazten delarik. Horrela, fase inorganikoa polimero-katearen baitan sartzen da.

Azkenik, grafting from teknika erabiliz, $\mathrm{Fe}_{2} \mathrm{O}_{3}$ nanopartikulen gainazalak PMMA polimero-kateekin eraldatu dira. Metodo honetan polimerokateak nanopartikularen edota surfaktantearen gainazalari aurrez txertatutako molekula hasarazle batetik hazten dira. Lehenik, hasarazlea txertatu zaie nanopartikulei gainazalean, eta ondoren, metil metakrilato monomeroa polimerizatu da hasarazletik, PMMA polimero-kateak dituzten $\mathrm{Fe}_{2} \mathrm{O}_{3}$ 
nanopartikulak lortuz. Nanopartikulen eraldaketa aztertzeko, Fourier-en transformatuaren infragorri espektroskopia (FTIR) eta analisi termograbimetrikoa (TGA) erabili dira kasu guztietan [11-14]. Hiru teknikak azaltzen dituen eskema 3. irudian ikus daiteke.

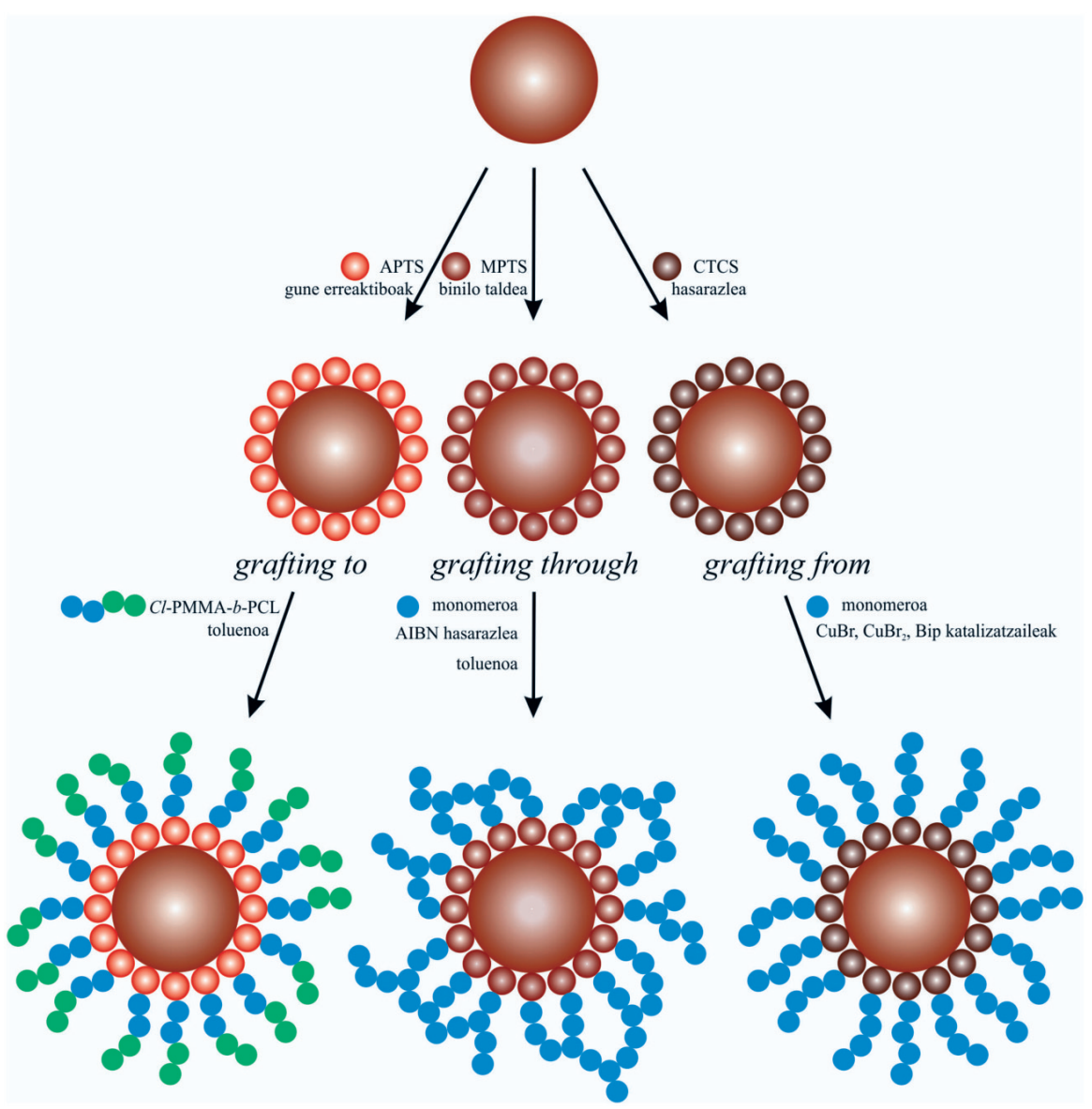

3. irudia. Nanopartikulak eraldatzeko jarraitutako metodo desberdinen deskribapena.

Nanopartikulak eraldatzeko hiru metodoekin lortutako emaitzak aztertuta esan genezake grafting to metodoa erabilita txertatze-dentsitate baxuak lortu direla, baina metodo azkarra eta erraza dela; grafting through-ri dagokionez, metodo honen desabantaila nagusia da polimero-kate linealen ordez, polimero-sareak osatzen dituztenez ezinezkoa dela txertatze-dentsitatea kalkulatzea, hala ere, hau ere metodo erraz eta egokia da nanoparti- 
kulen gainazala eraldatzeko; azkenik, grafting from teknikari dagokionez, metodo honek txertatze-dentsitatea kalkulatzea ahalbidetzen du, nanopartikulen gainazaletik hazi diren polimero-kateak bereiziak izan daitezkeelako. Gainera, grafting to metodoarekin konparatuz gero, txertatze-dentsitate altuagoak lortu dira, metodo hau aurrekoak baino konplexuagoa izan arren.

\section{NANOKONPOSATUEN FILM MEHEAK}

Behin nanopartikulak eraldatu ostean, nanokonposatu film meheak prestatzeari ekin zaio. Lan honetan, material nanokonposatuaren oinarri polimeriko gisa blokezko kopolimero desberdinak erabili dira: poli(estireno- $b$ - $\varepsilon$-kaprolaktona) (PS- $b$-PCL), poli(estireno- $b-4$ binil piridina) (PS$b$-P4VP), poli(estireno- $b$-metil metakrilatoa) (PS- $b$-PMMA), poli(estireno- $b$-butadieno- $b$-metil metakrilatoa) $(\mathrm{SBM})$ eta poli(isopreno- $b$-metil metakrilatoa) (PI- $b$-PMMA). Blokezko kopolimero bakoitzarekin nanokonposatu film meheak prestatu aurreko urratsa izan da blokezko kopolimero horiek sortutako nanoegiturak aztertzea. 4. irudian blokezko kopolimero bakoitzarekin lortutako nanoegiturak ikus daitezke; irudi horiek AFM bidez lortu dira.

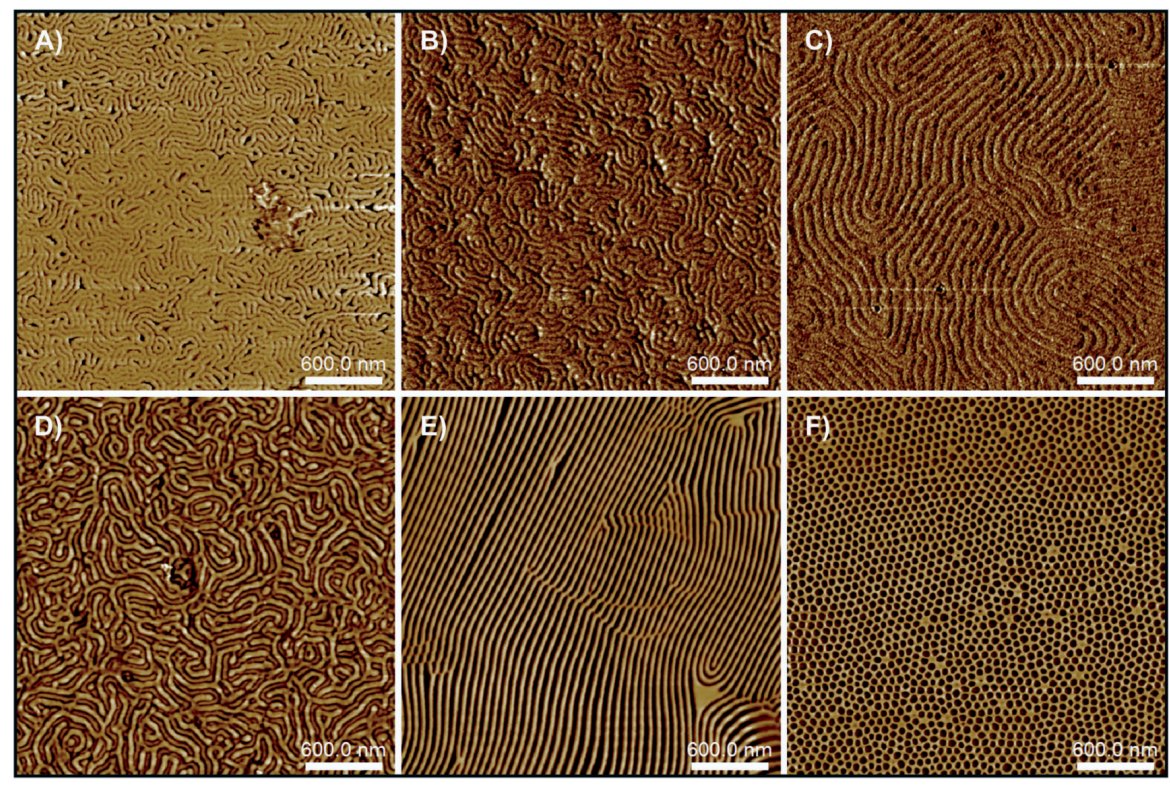

4. irudia. A) PS- $b$-PCLa $120^{\circ} \mathrm{C}-\tan 48 \mathrm{~h}-\mathrm{z}$, B) PS- $b$-P4VPa dioxano lurrunetan $48 \mathrm{~h}-\mathrm{z}, \mathrm{C})$ PS- $b$-PMMAa azetona lurrunetan $16 \mathrm{~h}-\mathrm{z}$ tratatu ondoren, D) SBM tratamendurik gabe, E) PI- $b$-PMMAa tratamendurik gabe eta F) PI- $b$-PMMAa 96 h-z azetona lurrunetan tratatu ondoren lortutako AFM fase-irudiak. 
Blokezko kopolimero eta nanopartikula magnetikoetan oinarritutako nanokonposatu film meheak: nanopartikulen dispertsioaren eragina

Ikus daitekeenez blokezko kopolimero bakoitzak morfologia desberdina sortzen du. Hori bakoitzaren izaeraren araberakoa da, hau da, blokeen arteko bateraezintasunaren, pisu molekularraren eta konposizioaren araberakoa, eta baita jasotako tratamenduaren araberakoa ere. PS- $b$-PCL eta PS- $b$-P4VP kopolimeroekin antzeko nanoegitura lamelarra lortu da, PS- $b$ PMMA kopolimeroarekin ere nanoegitura lamelarra lortu da, kasu honetan lamelak handiagoak direlarik. SBM triblokezko kopolimeroarekin ere nanoegitura lamelarra lortu da, kasu honetan berezitasuna blokezko kopolimeroaren hiru bloke desberdinak ikus daitezkeela izanik, S-B-M-B sekuentzia osatuz. PI- $b$-PMMA kopolimeroaren kasuan, inolako tratamendurik gabe egitura lamelarra lortu da, baina azetonarekin tratatu ostean, gainazalarekiko perpendikularki kokatuta dauden zilindroez osatutako nanoegiturara eraldatu da.

Behin blokezko kopolimeroak nanoegituratzea lortutakoan, nanokonposatuak prestatu dira, horretarako metodo desberdinak jarraituz eraldatutako nanopartikulak blokezko kopolimeroekin konbinatuz. 1. taulan burutu diren konbinaketak ikus daitezke.

1. taula. Nanokonposatuak osatzeko erabilitako blokezko kopolimeroak eta nanopartikulak, eraldatzeko erabilitako teknikarekin.

\begin{tabular}{ccc}
\hline Blokezko kopolimeroa & $\begin{array}{c}\text { Nanopartikulak eraldatzeko } \\
\text { teknika }\end{array}$ & Nanopartikulak \\
\hline PS- $b$-PCL & Grafting to & $\mathrm{Fe}_{2} \mathrm{O}_{3}$-PMMA- $b$-PCL \\
PS- $b$-P4V & Grafting through & $\mathrm{Fe}_{2} \mathrm{O}_{3}$-PS \\
PS- $b$-PMMA & Grafting through & $\mathrm{Fe}_{2} \mathrm{O}_{3}$-PMMA \\
SBM & Grafting through & $\mathrm{Fe}_{2} \mathrm{O}_{3}-\mathrm{PMMA}_{2}$ eta Fe $\mathrm{O}_{2}$-PS \\
PI- $b$-PMMA & Grafting from & $\mathrm{Fe}_{2} \mathrm{O}_{3}$-PMMA \\
\hline
\end{tabular}

Nanopartikulak gehitzeak blokezko kopolimeroaren nanoegituratzean duen eragina aztertzeko, PS- $b$-PCL/ $\mathrm{Fe}_{2} \mathrm{O}_{3}$-PMMA- $b$-PCL eta PS- $b$ $\mathrm{PMMA} / \mathrm{Fe}_{2} \mathrm{O}_{3}$-PMMA nanokonposatuen AFM irudiak aztertuko ditugu.

Irudi hauetan ikus daitekeenez, nanopartikulak gehitzeak eragin desberdinak izan ditzake blokezko kopolimeroaren morfologian. Batetik, $\mathrm{PS}-b$-PCL/ $\mathrm{Fe}_{2} \mathrm{O}_{3}$-PMMA- $b$-PCL-ren kasuan, nanopartikulak blokezko kopolimeroaren domeinuen interfasean kokatzen direnez, blokezko kopolimeroaren morfologian eragin gutxi dute. PS- $b$-PMMA/ $\mathrm{Fe}_{2} \mathrm{O}_{3}$-PMMA nanokonposatuaren kasuan, aldiz, nanopartikulak blokezko kopolimeroaren PMMA domeinuetan kokatu direnez, horrek domeinu horien puztea, hau da, bolumena handitzea, ekarri du, modu honetan bi domeinuen arteko bolumen-erlazioa aldatuz, eta honekin baita morfologia ere. 


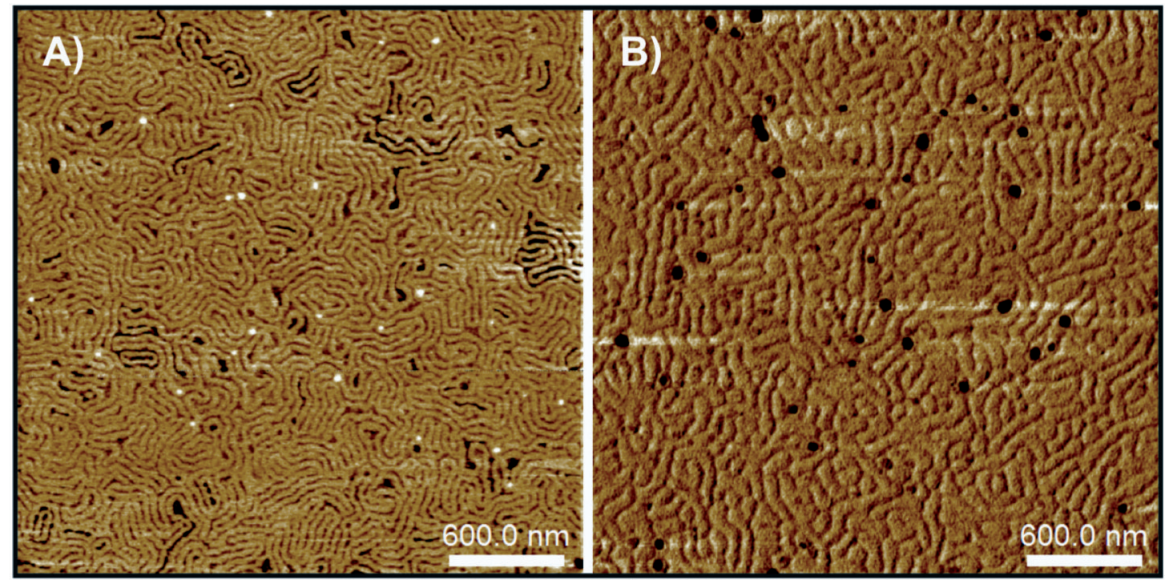

5. irudia. A) PS- $b$-PCL/Fe ${ }_{2} \mathrm{O}_{3}$-PMMA- $b$-PCL eta B) PS- $b$-PMMA/ $/ \mathrm{Fe}_{2} \mathrm{O}_{3}$ PMMA nanokonposatuen AFM fase-irudiak nanopartikulen ehunekoa pisuan $\%$ 5ekoa denean.

6. irudian ikus daitekeenez, nanopartikulak inolako eraldatzerik gabe gehitzean, nanopartikulek elkartzeko joera dute, agregatu handiak sortuz.

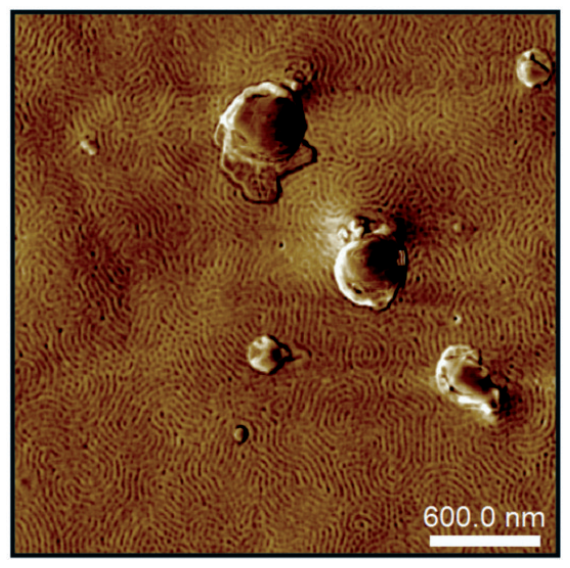

6. irudia. $\mathrm{PS}-b$ - $\mathrm{PCL} / \mathrm{Fe}_{2} \mathrm{O}_{3}$ nanokonposatuaren $\mathrm{AFM}$ fase-irudia.

Amaitzeko, nanokonposatu horien propietate magnetikoak ere aztertu dira. Horretarako, interferentzia kuantiko supereroale bidezko gailua (SQUID) edota lagin bibratzaileen magnetometro (VSM) karakterizazioteknikak erabili dira, zero-eremua-aplikatuz-hoztua/eremua-aplikatuz-hoz- 
Blokezko kopolimero eta nanopartikula magnetikoetan oinarritutako nanokonposatu film meheak: nanopartikulen dispertsioaren eragina

tua $(\mathrm{ZFC} / \mathrm{FC})$ prozedura jarraituz eta momentua eremu magnetikoaren arabera adierazten duten entseguak burutu dira. Emaitzek erakutsi dute nanokonposatu organiko/inorganikoek giro-tenperaturan portaera superparamagnetikoa dutela, eta ferromagnetikoa tenperatura baxutan. Adibide gisa 7. irudia daukagu, bertan kontzentrazioa pisuan \% 5ekoa duen $\mathrm{SBM} / \mathrm{Fe}_{2} \mathrm{O}_{3}$ PMMA nanokonposatuaren VSM bidezko emaitzak ikus daitezke. Gainontzeko nanokonposatuekin lortutako emaitzak bibliografian aurki daitezke $[12,14,15]$.
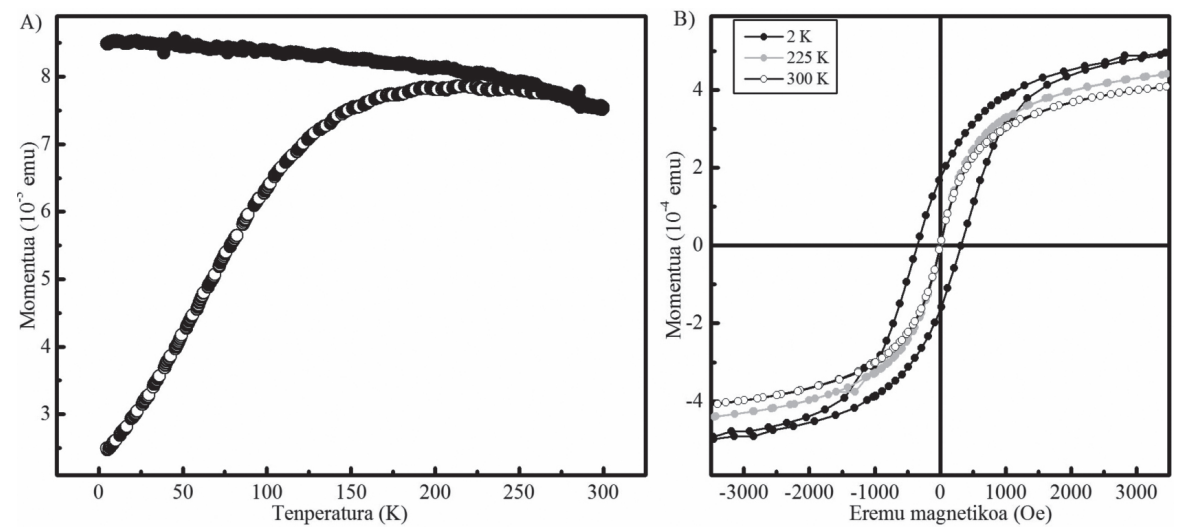

7. irudia. Pisuan $\%$ 5eko kontzentrazioa duen $\mathrm{SBM} / \mathrm{Fe}_{2} \mathrm{O}_{3}$-PMMA nanokonposatuaren $\mathrm{A}) \mathrm{ZFC} / \mathrm{FC}$ eta $\mathrm{B}$ ) momentua $v s$ eremu magnetikoa entseguen emaitzak.

\section{ONDORIOAK}

Ikerketa-lan honetatik hainbat ondorio lor daitezke, bai nanopartikulen eraldatzeari dagokionez, bai blokezko kopolimeroen nanoegituratzeari dagokionez.

Nanopartikulen eraldaketan, hiru metodoek erakutsi dute beraien baliagarritasuna nanopartikulen gainazalak eraldatzeko orduan, nanopartikula eta blokezko kopolimeroen arteko bateragarritasuna hobetuz eta nanopartikulen dispertsio egokia ahalbidetuz. Hala ere, grafting to metodoarekin txertatze-dentsitate baxuak lortu dira; ondorioz, nanopartikulak nagusiki nanoegituratutako kopolimeroaren domeinu desberdinen arteko interfaseetan kokatu dira. Grafting through metodoarekin, nahiz eta nanopartikulen agregatu txikiak agertu blokezko kopolimeroan zehar dispertsatutakoan, orokorrean dispertsio ona lortu da. Are gehiago, nanopartikulak blokezko kopolimeroan aukeratutako domeinuan kokatzea lortu da. Azkenik, grafting from metodoarekin, grafting to metodoarekin baino txertatze-dentsitate altuagoak lortu dira; gainera, metodo honek txertatutako 
polimero-katearen luzera erregulatzeko aukera ematen du, nanopartikulak selektiboki kokatuz.

Blokezko kopolimeroari nanopartikulak gehitzerakoan ikusi da morfologia-aldaketak eman daitezkeela, batez ere nanopartikulak domeinuetako batean selektiboki kokatuak izan badira. Nanopartikulak domeinuetako batean kokatzeak domeinu horren puztea eragiten du, blokeen arteko bolumen-erlazioa aldatuz, eta horrek morfologia-aldaketa ekar dezake. Nanopartikulak gehitzeak blokeen arteko interakzioetan edota kopolimeroaren eta substratuaren artekoetan ere eragin dezake, morfologia-aldaketa eraginez edota nanoegituraren orientazioa aldatuz.

Amaitzeko, nanokonposatuetan material magnetikoen propietateak antzeman direnez, esan daiteke nanopartikulen propietate magnetikoak nanokonposatuari transferituak izan direla.

\section{ESKER ONAK}

Artikulu hau Euskal Herriko Unibertsitateak (UPV/EHU) finantzatutako doktoratu aurreko diru-laguntzari (Ikertzaileak Prestatzeko Laguntzak 2011 (PIF/UPV/11/030)) eta Espainiar Ekonomia eta Lehiakortasun Ministerioaren eta Europar Batasunaren (MAT2015-66149-P) finantziazioari esker burutu da.

\section{BIBLIOGRAFIA}

[1] LUO M. eta EPPS T.H. 2013. «Directed Block Copolymer Thin Film SelfAssembly: Emerging Trends in Nanopattern Fabrication». Macromolecules, 46, 7567-7579.

[2] SARKAR B. eta ALEXANDRIDIS P. 2015 «Block copolymer-nanoparticle composites: Structure, functional properties, and processing». Progress in Polymer Science, 40, 33-62.

[3] LEIBLER, L. 1980. «Theory of Microphase Separation in Block Copolymers». Macromolecules, 13, 1602-1617.

[4] MATSEN, M.W. eta BATES, F.S. 1996. «Unifying weak- and strong-segregation block copolymer theories». Macromolecules, 29, 1091-1098.

[5] ETXEBERRIA, H., TERCJAK, A., MONDRAGON, I., ECEIZA, A. eta KORTABERRIA, G. 2014. «Electrostatic force microscopy measurements of CdSe-PS nanoparticles and CdSe-PS/poly(styrene- $b$-butadiene- $b$-styrene) nanocomposites». Colloid Polym Sci, 292, 229-234.

[6] GUTIERREZ, J., TERCJAK, A., GARCIA, I. eta MONDRAGON, I. 2009. «The effect of thermal and vapor annealing treatments on the self-assembly of TiO2/PS-b-PMMA nanocomposites generated via the sol-gel process». Nanotechnology, 20, 225603 (9pp). 
Blokezko kopolimero eta nanopartikula magnetikoetan oinarritutako nanokonposatu film meheak: nanopartikulen dispertsioaren eragina

[7] XU, H., PANG, X., HE, Y., HE, M., JUNG, J., XIA, H. eta LIN, Z. 2015. «An Unconventional Route to Monodisperse and Intimately Contacted Semiconducting Organic-Inorganic Nanocomposites». Angew Chem Int Edit, 54, 4636-4640.

[8] SHI, D., SADAT, M.E., DUNN, A.W. eta MAST D.B. 2015. «Photo-fluorescent and magnetic properties of iron oxide nanoparticles for biomedical applications». Nanoscale, 7, 8209-8232.

[9] PARK, M.J., CHAR, K., PARK, J. eta HYEON, T. 2006. «Effect of the Casting Solvent on the Morphology of Poly(styrene- $b$-isoprene) Diblock Copolymer/Magnetic Nanoparticle Mixtures». Langmuir, 22, 1375-1378.

[10] LAUTER, V., MÜLLER-BUSCHBAUM, P., LAUTER, H. eta PETRY, W. 2011. «Morphology of thin nanocomposite films of asymmetric diblock copolymer and magnetite nanoparticles». J Phys-Condens Mat, 23, 254215 (6pp).

[11] BARANDIARAN, I., CAPPELLETTI, A., STRUMIA, M., ECEIZA, A. eta KORTABERRIA, G. 2014. "Generation of nanocomposites based on (PMMA-b-PCL)-grafted $\mathrm{Fe}_{2} \mathrm{O}_{3}$ nanoparticles and PS-b-PCL block copolymer». Eur Polym J, 58, 226-232.

[12] BARANDIARAN, I. eta KORTABERRIA, G. 2015 «Synthesis and characterization of nanostructured PS- $b-\mathrm{P} 4 \mathrm{VP} / \mathrm{Fe}_{2} \mathrm{O}_{3}$ thin films with magnetic properties prepared by solvent vapor annealing». RSC $A d v, \mathbf{5}, 95840-95846$.

[13] BARANDIARAN, I. eta KORTABERRIA, G. 2015 «Selective placement of magnetic $\mathrm{Fe}_{3} \mathrm{O}_{4}$ nanoparticles into the lamellar nanostructure of PS- $b$ PMMA diblock copolymer». Eur Polym J, 68, 57-67.

[14] BARANDIARAN, I., GRANA, E., KATSIGIANNOPOULOS, D., AVGEROPOULOS, A. eta KORTABERRIA, G. 2016 «Nanocomposites based on nanostructured PI- $b$-PMMA copolymer and selectively placed PMMA-modified magnetic nanoparticles: Morphological and magnetic characterization». Eur Polym J, 75, 514-524.

[15] BARANDIARAN, I. eta KORTABERRIA, G. 2016 «Magnetic nanocomposites based on poly(styrene- $b$-butadiene- $b$-methyl methacrylate) and modified $\mathrm{Fe}_{2} \mathrm{O}_{3}$ nanoparticles». Eur Polym J, 78, 340-351. 